\title{
Role of transient receptor potential ankyrin 1 channels in Alzheimer's disease
}

\author{
Kuan-I Lee ${ }^{1}$, Hsueh-Te Lee ${ }^{2}$, Hui-Ching Lin ${ }^{1}$, Huey-Jen Tsay ${ }^{3}$, Feng-Chuan Tsai ${ }^{2,4}$, Song-Kun Shyue ${ }^{5}$ \\ and Tzong-Shyuan Lee ${ }^{1,6^{*}}$
}

\begin{abstract}
Background: Transient receptor potential ankyrin 1 (TRPA1) channel plays an important role in pain and inflammation. However, little is known about the significance of the TRPA1 channel in the pathophysiology of Alzheimer's disease (AD).

Methods: Wild-type (WT), TRPA1 ${ }^{-1}$, amyloid precursor protein (APP)/presenilin 1 (PS1) transgenic (APP/PS1 Tg) mice, the mouse model of $A D$, and APP/PS1 Tg/TRPA1 ${ }^{-1-}$ mice were used to examine the role of TRPA1 in pathogenesis of AD. Western blot was used for protein expression; immunohistochemistry was used for histological examination. The mouse behaviors were evaluated by locomotion, nesting building, $Y$-maze and Morris water maze tests; levels of interleukin (IL)-1 $13, I L-4, I L-6$ and IL-10 and the activities of protein phosphatase 2B (PP2B), NF-KB and nuclear factor of activated T cells (NFAT) were measured by conventional assay kits; Fluo-8 NW calcium $\left(\mathrm{Ca}^{2+}\right)$ assay kit was used for the measurement of intracellular $\mathrm{Ca}^{2+}$ level in primary astrocytes and HEK293 cells.

Results: The protein expression of TRPA1 channels was higher in brains, mainly astrocytes of the hippocampus, from APP/PS1 Tg mice than WT mice. Ablation of TRPA1-channel function in APP/PS1 Tg mice alleviated behavioral dysfunction, A $\beta$ plaque deposition and pro-inflammatory cytokine production but increased astrogliosis in brain lesions. TRPA1 channels were activated and $\mathrm{Ca}^{2+}$ influx was elicited in both astrocytes and TRPA1-transfected HEK293 cells treated with fibrilized $A \beta_{1-42}$; these were abrogated by pharmacological inhibition of TRPA1 channel activity, disruption of TRPA1 channel function or removal of extracellular $\mathrm{Ca}^{2+}$. Inhibition of TRPA1 channel activity exacerbated $A \beta_{1-42}$-induced astrogliosis but inhibited $A \beta_{1-42}$-increased PP2B activation, the production of pro-inflammatory cytokines and activities of transcriptional factors NF-KB and NFAT in astrocytes and in APP/PS1 Tg mice. Pharmacological inhibition of PP2B activity diminished the fibrilized $A \beta_{1-42}$-induced production of pro-inflammatory cytokines, activation of NF-KB and NFAT and astrogliosis in astrocytes.
\end{abstract}

Conclusions: TRPA $1-\mathrm{Ca}^{2+}-$ PP2B signaling may play a crucial role in regulating astrocyte-derived inflammation and pathogenesis of AD.

Keywords: Transient receptor potential ankyrin 1, Calcium, Alzheimer's disease, Inflammation, Protein phosphatase 2B

\section{Background}

Alzheimer's disease (AD), a progressive neurodegenerative disease, is the most common cause of dementia [1]. The typical symptoms of $\mathrm{AD}$ include learning and memory loss and cognitive impairment $[1,2]$. Amyloid- $\beta(A \beta)$ plaque deposition is one of the major pathological hallmarks in $A D$ [2-4]. $A \beta$ is generated from amyloid precursor protein (APP) by $\beta$-site APP cleavage enzyme 1 (BACE1) and

\footnotetext{
* Correspondence: tslee@ym.edu.tw

${ }^{1}$ Department of Physiology, School of Medicine, National Yang-Ming University, Taipei, Taiwan

${ }^{6}$ Genome Research Center, National Yang-Ming University, Taipei, Taiwan Full list of author information is available at the end of the article
}

presenilin 1 (PS1) $[3,5]$. The toxic $A \beta$ activates astrocytes and microglia to trigger chronic inflammation, thereby releasing cytokines, pro-inflammatory mediators and reactive oxygen species (ROS) and leading to progression of $\mathrm{AD}$ [6-10]. Several lines of evidence suggest that $A \beta$-mobilized calcium $\left(\mathrm{Ca}^{2+}\right)$ flow is closely associated with the inflammatory response in astrocytes [11-13]. On $A \beta$ stimulation, elevated intracellular $\mathrm{Ca}^{2+}$ level promotes cytokine secretion by activating protein phosphatase $2 \mathrm{~B}$ ( $\mathrm{PP} 2 \mathrm{~B}$, also called calcineurin) and its downstream NF- $\mathrm{kB}$ and nuclear factor of activated T cells (NFAT) [14-16]. However, which type of cation channel is responsible for the 
$\mathrm{A} \beta$-activated $\mathrm{Ca}^{2+}$ signaling and inflammation remains for further investigation.

Transient receptor potential ankyrin 1 (TRPA1) channel is a type of nonselective transmembrane cation channel with multiple ankyrin repeats on its N-terminal [17-20]. TRPA1 channel is expressed in primary sensory neurons and non-neuronal cells and may be a sensor for detecting ROS, cold temperature and cannabinoids [21-24]. Upon detection of these signals, the TRPA1 channel is activated, which results in increased intracellular $\mathrm{Ca}^{2+}$ levels and activated downstream signaling cascades [17-20]. In the brain, the TRPA1 channel plays an important role in regulating brain development and the physiological function of astrocytes [24, 25]. In addition, it may be a key gatekeeper in regulating the inflammatory response with stimuli including bacterial endotoxin, environmental irritants or inflammatory mediators [26-28]. Recently, AD research has focused on the emerging role of $\mathrm{Ca}^{2+}$-related signaling pathways in the pathogenesis of $\operatorname{AD}[29,30]$. However, the role and underlying molecular mechanism(s) of the TRPA1 $-\mathrm{Ca}^{2+}$ signaling cascade in AD pathogenesis are still elusive.

In this study, we aimed to investigate the role of TRPA1 channels in $\mathrm{AD}$ pathogenesis and the possible molecular mechanisms in a mouse model. We determined the expression of TRPA1 channels in vivo by using wild-type (WT) and APP/PS1 transgenic (Tg) mice, then investigated whether the TRPA1 channel plays a role in the development of AD by using APP/PS1 Tg and APP/PS1 Tg/TRPA1 ${ }^{-/-}$mice. Finally, we assessed the importance of TRPA1 and the potential mechanism underlying the regulation of $A \beta$ mediated inflammation in mice and astrocytes.

\section{Methods}

\section{Reagents}

Rabbit antibody for TRPA1 (NB110-40763) was from Novus (Littleton, CO, USA). Goat antibody for Akt (sc1619), rabbit antibodies for PP2B (sc-9070), mouse antibodies for glial fibrillary acidic protein (GFAP, sc166481), goat anti-rabbit FITC-conjugated (sc-2012), goat anti- mouse Texas red-conjugated (sc-2781) and FITC-conjugated (sc-2010) antibodies were from Santa Cruz Biotechnology (Santa Cruz, CA, USA). Mouse antibodies for GFAP (MAB360), NeuN (MAB3770), ionized calcium-binding adapter molecule 1 (IBA-1, MABN92), von Willebrand factor (vWF, MAB7356), and the cellular PP2B activity kit were from Millipore (Darmstadt, Germany). Rabbit LDLR-related protein 1 (LRP-1, L2170), mouse antibody for $\alpha$-tubulin (T-9026), bovine serum albumin (BSA), phosphatase inhibitor cocktails 1 and 2, HC030031, allyl isothiocyanate (AITC), ethylene glycol tetraaceticacid (EGTA), ethylenediaminetetraacetic acid (EDTA), cyclosporine (CsA) and fenvalerate (Fen) were from Sigma-Aldrich (St. Louis, MO, USA). Mouse antibody for A $\beta$ (SIG-39320-200) was from Covance (Dedham, MA, USA). Rabbit antibody for $\beta$-APP C-terminal fragment ( $\beta C T F, 802801)$ was from BioLegend (San Diego, CA, USA). Mouse antibody for ATP-binding cassette transporter A1 (ABCA1, ab18180), IL-4 (ab9622) and IL-10 (ab9969) were from Abcam (Cambridge, MA, UK). Rabbit antibody for apolipoprotein E (apoE, 1930-5) was from Epitomics (Burlingame, CA, USA). Mouse anti-phosphor-Akt (587 F11) was from Cell Signaling (Danvers, MA, USA). Retrieval buffer was from Biocare Medical (Concord, CA, USA). The mounting medium with DAPI was from Vector Laboratories (Burlingame, CA, USA). TurboFect was from Fermentas (Glen Burnie, MD, USA). The ELISA kit for NF$\kappa \mathrm{B}$ activity was from Cayman Chemical (Ann Arbor, MI, USA) and for NFAT activity was from Active Motif (Carlsbad, CA, USA). ELISA kits for IL-1 $\beta$, IL-4, IL-6 and IL-10 and mouse antibodies for IL-1 $\beta$ (AF-401-NA) and IL-10 (AF-406-NA) were from R\&D systems (Minneapolis, MN, USA). Quest ${ }^{\text {tm }}$ Fluo-8 NW calcium assay kit was from AAT Bioquest (Sunnyvale, CA, USA).

\section{Mice}

The investigation conformed to the Guide for the Care and Use of Laboratory Animals (Institute of Laboratory Animal Resources, eighth edition, 2011), and all animal experiments were performed in accordance with the approved guidelines by the Animal Care and Utilization Committee of the National Yang-Ming University (\#1031269). B6.Cg$\mathrm{Tg}$ (APPswe, PSEN1dE9)85Dbo/J (APP/PS1 Tg) mice and $\mathrm{TRPA}^{-/-}$mice were purchased from Jackson Laboratory (Bar Harbor, ME, USA) and were backcrossed to C57BL mice for at least 10 generations to ensure genetic homogeneity. For APP/PS1 Tg/TRPA1 ${ }^{-/-}$mice, $\mathrm{TRPA}^{-/-}$mice were crossed with the APP/PS1 Tg background, and the genotypes were confirmed by PCR of genomic DNA. Mice were housed in barrier facilities, maintained on a 12-h/12-h dark cycle. Temperature $\left(22{ }^{\circ} \mathrm{C}\right)$ and humidity $(40-60 \%)$ of the vivarium were tightly controlled. Mice were group-housed 3-4 per cage and fed a regular chow diet, which contained $4.5 \%$ fat by weight $(0.02 \%$ cholesterol) (Newco Distributors, Redwood, CA, USA). At the end of the experiment, mice were euthanized with $\mathrm{CO}_{2}$, then brains were harvested for histological analysis and stored at $-80{ }^{\circ} \mathrm{C}$. The isolated brains were homogenized and lysates were subjected to western blot analysis.

\section{Western blot analysis}

Cells and brain tissues were lysed in immunoprecipitation lysis buffer $(50 \mathrm{mmol} / \mathrm{L}$ Tris $\mathrm{pH} 7.5,5 \mathrm{mmol} / \mathrm{L}$ EDTA, $300 \mathrm{mmol} / \mathrm{L} \mathrm{NaCl}, 1 \%$ Triton X-100, $1 \mathrm{mmol} / \mathrm{L}$ phenylmethylsulfonyl fluoride, $10 \mu \mathrm{g} / \mathrm{mL}$ leupeptin and $10 \mu \mathrm{g} / \mathrm{mL}$ aprotinin). Aliquots of brain lysates or cell lysates were separated on SDS-PAGE, transferred to membranes and immunoblotted with primary antibodies 
(1:1000), then horseradish peroxidase-conjugated secondary antibody (1:1000). Bands were revealed by use of an enzyme-linked chemiluminescence detection kit (PerkimElmer, Waltham, MA) and density was quantified by use of Imagequant 5.2 (Healthcare Bio-Sciences, Philadelphia, PA).

\section{Immunohistochemistry staining}

The brain sections were fixed in $4 \%$ paraformaldehyde and $15-\mu \mathrm{m}$ cross sections were prepared. Sections were incubated with retrieval buffer for $10 \mathrm{~min}$, blocked with $2 \%$ BSA for $60 \mathrm{~min}$ and incubated with primary antibody (1:100) overnight at $4{ }^{\circ} \mathrm{C}$, then FITC- or Texas redconjugated secondary antibody (1:400) for $1 \mathrm{~h}$ at $37{ }^{\circ} \mathrm{C}$. Antigenic sites were visualized under a Nikon TE2000U microscope (Tokyo) with QCapture Pro 6.0 software (QImaging, BC, Canada).

\section{Fibrilization of $A \beta_{1-42}$}

$A \beta_{1-42}$ was purchased from American Peptide Co. (Sunnyvale, CA, USA), solubilized in sterile water $(1 \mathrm{mg} / \mathrm{mL})$ and incubated 1 to 7 days at $37^{\circ} \mathrm{C}$ for fibrillation as described [31-33]. The level of A $\beta$ fibrilization on a $16.5 \%$ tricine gel was examined by western blot analysis (Additional file 1: Figure S1).

\section{Cell culture}

The primary culture of astrocytes and neurons was prepared as described [24, 34]. Briefly, the cortex and hippocampus were isolated from pups on postnatal 1 day and loosely homogenized by use of a sterile razor blade in DMEM/F12 (HyClone, Logan, UT). Tissues were digested with $0.01 \%$ trypsin and incubated at $37{ }^{\circ} \mathrm{C}$ for $25 \mathrm{~min}$; the cell suspension was titrated by use of a 70- $\mu \mathrm{m}$ nylon mesh. Isolated cells were seeded onto 75-mm flasks and incubated for 7 days in DMEM/F12 supplemented with 10 \% FBS, $100 \mathrm{U} / \mathrm{mL}$ penicillin and $100 \mu \mathrm{g} / \mathrm{mL}$ streptomycin at $37{ }^{\circ} \mathrm{C}$. Cells were re-suspended, followed by orbital shaking at $180 \mathrm{rpm}$ for $24 \mathrm{~h}$ to remove microglia and oligodendrocytes. The purified astrocytes that tightly adhered to the bottom of the flasks were then detached with trypsin and seeded onto culture dishes and incubated for an additional 7 days to return to a resting state. The primary neuron culture was prepared as follows: the cortex was isolated from pups on postnatal 1 day and loosely homogenized by use of a sterile razor blade in DMEM (HyClone, Logan, UT). Isolated cells were seeded onto $3.5-\mathrm{cm}$ dishes and incubated in Neurobasal media supplemented with $2 \%$ B27 supplement, $0.25 \%$ GlutaMAX, $10 \%$ FBS, $100 \mathrm{U} / \mathrm{mL}$ penicillin and $100 \mu \mathrm{g} / \mathrm{mL}$ streptomycin (Thermo Fisher Scientific, Waltham, MA, USA) at $37{ }^{\circ} \mathrm{C}$. Cells were treated with cytosine-1- $\beta$-D-arabinofuranoside $(10 \mu \mathrm{M})$ from day 2 and half the medium was changed every 3 days for 14 days' culture. Human embryonic kidney 293 (HEK293) cells and mouse brain microvascular endothelial cells (BMECs), bEnd.3 cells, were cultured in DMEM supplemented with $10 \%$ FBS, $100 \mathrm{U} / \mathrm{mL}$ penicillin and $100 \mu \mathrm{g} / \mathrm{mL}$ streptomycin. The growth media was replaced every other day.

\section{Plasmid construction and transient transfection}

The coding region for the human TRPA1 DNA fragment was cloned into a pCMV5 N-Flag vector with MluI and HindIII restriction sites. The sequence of isolated DNA fragments was confirmed by sequence analysis. TurboFect was used for transient transfection experiments according to the manufacturer's instructions. Briefly, $1 \mu \mathrm{g}$ of vector or TRPA1 plasmid was transfected into HEK293 cells. Transfected cells were used in further experiments.

\section{Detection of $\mathrm{Ca}^{2+}$ influx}

Primary astrocytes or HEK293 cells were pretreated with Fluo-8NW dye for $1 \mathrm{~h}$, then medium was replaced with fresh medium containing test compounds. The intensity of fluorescence was evaluated by fluorometry (Molecular Devices, Sunnyvale, CA, USA) with 490-nm excitation and 525-nm emission. Images were captured under a TE2000-U fluorescence microscope and quantified with use of QCapture Pro 6.0.

\section{Measurement of PP2B activity}

The activity of PP2B in primary astrocytes or fresh brain lysates was measured by use of a cellular PP2B activity kit.

\section{Measurement of inflammatory cytokines}

The concentrations of inflammatory cytokines including IL-1 $\beta$, IL-4, IL- 6 and IL-10 in culture medium or brain lysates were measured by use of ELISA kits.

Measurement of DNA-binding activity on NF-KB and NFAT The DNA-binding activity of NF- $\mathrm{KB}$ and NFAT in primary astrocytes and brain was measured by use of ELISA kits.

\section{Immunocytochemical staining}

Primary astrocytes were fixed with $4 \%$ paraformaldehyde for $30 \mathrm{~min}$, blocked with $2 \% \mathrm{BSA}$ for $30 \mathrm{~min}$ and incubated with primary antibodies (1:100), then FITC- or Texas redconjugated secondary antibodies (1:400). Cellular images were viewed under a TE2000-U fluorescence microscope and quantified with use of QCapture Pro 6.0.

\section{Open field activity}

The locomotor activity of mice was assessed in a cage (length $\times$ width $\times$ height: $28.5 \times 28.5 \times 30 \mathrm{~cm}$ ). Mice were placed in the central of the cage and allowed to explore the open field for $5 \mathrm{~min}$. The behavior was recorded by video, and the movement distance, percentage of resting 
time in the zone and trajectory were calculated for each mouse by use of Smart v3.0 software with the Panlab Harvard apparatus (Cornellà, Barcelona, Spain). The floor and internal walls were cleaned with ethanol between each trial.

\section{Nest-building test}

The nest-building test was performed as described [35]. Each mouse was housed in single cages containing two pieces of cotton $(5 \times 5 \mathrm{~cm})$. The presence and quality of nests built were recorded by the nesting score, measured on a 5 -point scale: $1=$ cotton not noticeably touched, 2 = cotton partially torn up, 3 = mostly shredded cotton but often no identifiable nest location, $4=$ a markedly nesting site but flat nest, and $5=\mathrm{a}$ (near) perfect nest. Nesting score was recorded manually at 72 -h intervals.

\section{Y-maze test}

The Y-maze test was performed as described [36]. The Y-maze apparatus consists of three arms of channels made of stainless steel joined in the middle to form a "Y" shape. The mice were placed into one of the arms (start arm) and allowed to explore the maze with only one of the arms closed for $10 \mathrm{~min}$ (training trial). After $3 \mathrm{~h}$, mice were placed back in the start arm of the $\mathrm{Y}$ maze. Then, mice were allowed to explore all three arms freely for $5 \mathrm{~min}$ (test trial). The number of entries into each arm, the distance of movement and the first choice of entry were assessed in video recordings.

\section{Morris water maze (MWM)}

MWM was performed as described [36]. A large circular tank (0.8 $\mathrm{m}$ diameter, $0.4 \mathrm{~m}$ depth) was filled with water (25 $\pm 1{ }^{\circ} \mathrm{C}, 20 \mathrm{~cm}$ depth), and the escape platform $(8 \times$ $4 \mathrm{~cm}$ ) was submerged $1 \mathrm{~cm}$ below the surface. The training section was monitored by a video system. The escape latency and trajectory of swimming were recorded for each mouse. The hidden platform was located at the center of one of the four quadrants in the tank. The location of the platform was fixed throughout the testing. Mice had to navigate using extra-maze cues that were placed on the walls of the maze. From days 1 to 4, mice went through three trials with an inter-trial interval of $5 \mathrm{~min}$. The mouse was placed into the tank facing the side wall randomly at one of four start locations and allowed to swim until it found the platform or for a maximum of $120 \mathrm{sec}$. Mice that failed to find the platform within $120 \mathrm{sec}$ were guided toward the platform. The animal then remained on the platform for $20 \mathrm{sec}$ before being removed from the pool. The day after the hidden platform training, a probe trial was conducted to determine whether the mouse used a spatial strategy to find the platform. On day 5 , the platform was removed from the pool and the mouse was allowed to swim freely for $120 \mathrm{sec}$. The proportion of time spent in each quadrant of the pool and the number of times the mouse crossed the former position of the hidden platform were recorded.

\section{Statistical analysis}

Results are presented as mean \pm SEM. Data from cell studies were evaluated by non-parametric tests. MannWhitney $U$ test was used to compare 2 independent groups. Kruskal-Wallis followed by Bonferroni post-hoc analyses was used to account for multiple testing. Data from animal studies were evaluated by parametric tests. Two-way ANOVA followed by LSD test was used for multiple comparisons. The reagent effect and genotypic effect were two independent factors for this analysis. SPSS v20.0 (SPSS Inc, Chicago, IL) was used for analysis. Differences were considered statistically significant at $P<0.05$.

\section{Results}

The expression of TRPA1 channels is upregulated in astrocytes of $A D$ lesions

To explore the possible participation of TRPA1 channels in the pathogenesis of $\mathrm{AD}$, we investigated the expression and distribution of TRPA1 channels in brains from WT and APP/PS1 Tg mice. The protein level of TRPA1 channels was higher in APP/PS1 Tg than WT mice at 8 months old (Fig. 1a, $n=6, P<0.05$ ). However, the protein level did not differ between APP/PS1 Tg and WT mice at 3 months old (Additional file 1: Figure S2, $n=6, P>0.05)$. In the cortex, TRPA1 channels were expressed in endothelial cells of both WT and APP/PS1 Tg mice (Fig. 1b, c). However, the immunoreactivity of TRPA1 channels in neurons was observed only in APP/ PS1 Tg mice (Fig. 1b, c). In the hippocampus, TRPA1 channels were expressed in astrocytes of both WT and APP/PS1 Tg mice; however, TRPA1 level in hippocampus astrocytes was greater in APP/PS1 Tg than WT mice (Fig. 1b, c). In WT mice, the protein level of TRPA1 was much lower in neurons than astrocytes and BMECs (Additional file 1: Figure S3). TRPA1 may play an important role in astrocyte biology in AD pathogenesis.

\section{Genetic loss of function of TRPA1 channels on an APP/ PS1 Tg background improves nest building and spatial learning and memory}

To assess the effect of TRPA1 channels in the pathophysiology of $\mathrm{AD}$, we generated APP/PS1 Tg/TRPA $1^{-1-}$ mice (Fig. 2a). APP/PS1 Tg/TRPA1 ${ }^{-/-}$mice showed better performance in nest building than APP/PS1 Tg mice at 8 months old (Fig. $2 \mathrm{~b}, \mathrm{c}, n=8, P<0.05$ ). In the Y-maze test, 8-month-old APP/PS1 Tg/TRPA1 ${ }^{-/-}$mice showed increased preference for first entry to a novel arm; the ratio of entry number and moving distance in the novel arm was greater in these mice than in 8-month-old APP/PS1 
A

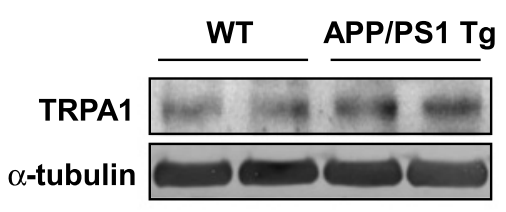

B

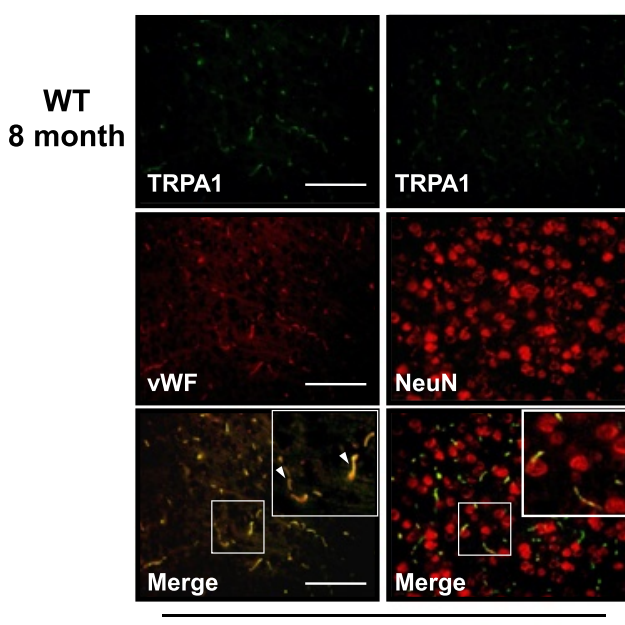

Cortex

C

APP/PS1 Tg 8 month
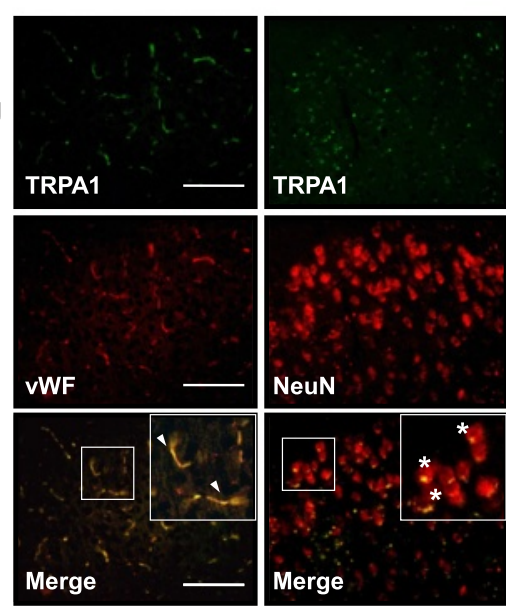

Cortex
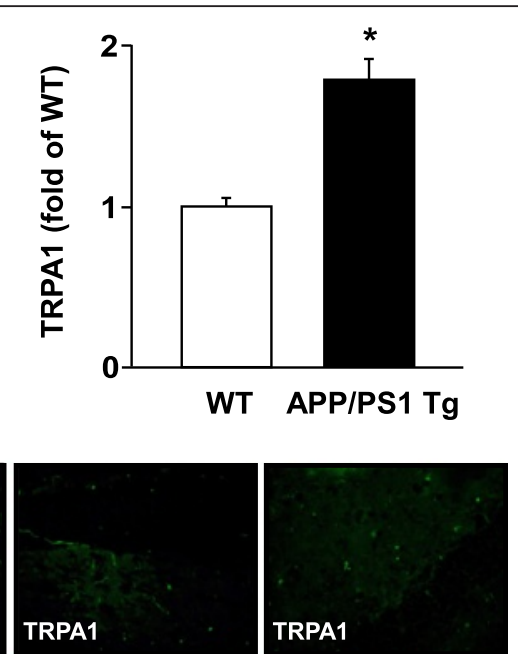

TRPA

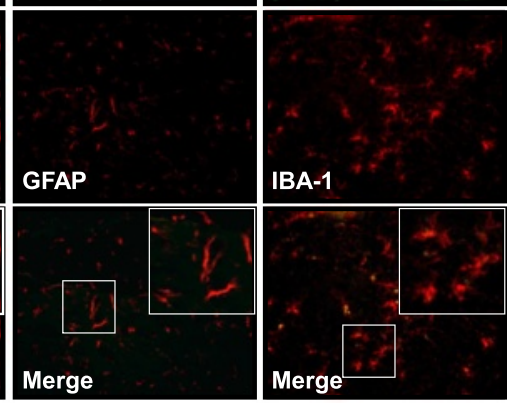

Hippocampus
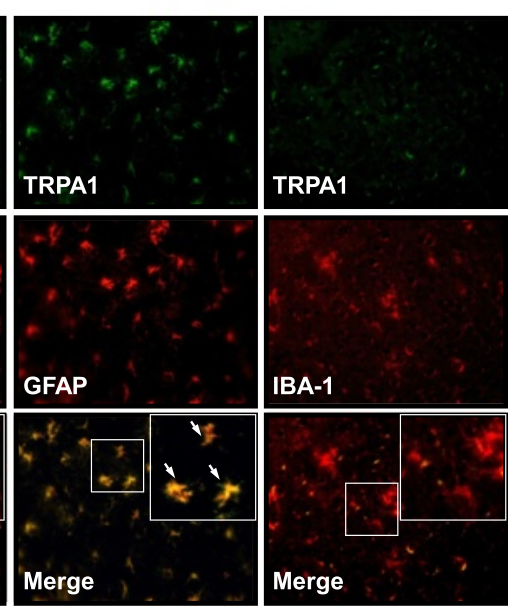

Hippocampus

Fig. 1 Expression and localization of TRPA1 channels in wild-type (WT) and APP/PS1 Tg mice. (a) Brains were harvested from WT and APP/PS1 Tg mice at 8 months old. Western blot analysis of protein levels of TRPA1 and a-tubulin. Data are mean \pm SEM from 6 mice in each group. *, $P<0.05$ vs. WT mice. (b, c) Immunohistochemistry of specimens of cortex and hippocampus from 8-month-old WT and APP/PS1 Tg mice with the antibodies anti-TRPA1, anti-vWF (endothelial cell marker), anti-NeuN (neuron marker), anti-GFAP (astrocyte marker) and anti-IBA-1 (microglia marker), then FITC- or Texas red-conjugated secondary antibody. Bar $=50 \mu \mathrm{m}$. VWF-positive cells denoted endothelial cells, NeuN-positive cells denoted neurons, and GFAP-positive cells denoted astrocytes, as indicated by arrowheads, stars or arrows, respectively

Tg mice (Fig. 2d-g, $n=8, P<0.05$ ). Next, the MWM test was performed to evaluate the ability of spatial learning and memory of mice. With the hidden platform test, both APP/PS1 $\mathrm{Tg}$ and APP/PS1 Tg/TRPA1 ${ }^{-/-}$mice learned the location of the hidden platform on day 3 and 4; however, 8month-old APP/PS1 Tg/TRPA1 ${ }^{-/}$mice showed shorter escape latencies, which indicates better learning patterns, than APP/PS1 Tg mice with a 4-day training (Fig. $2 \mathrm{~h}, n=8$, 


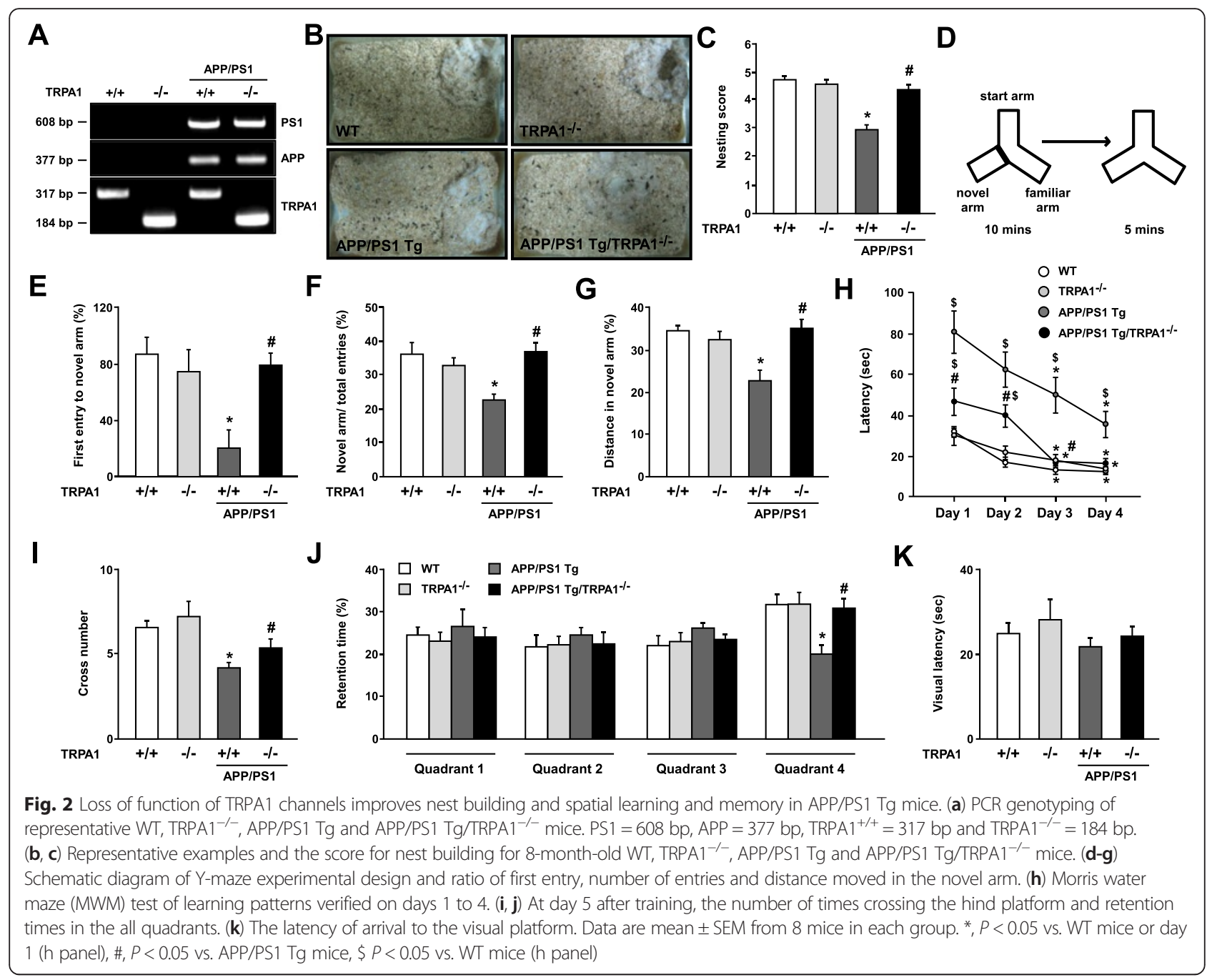

$P<0.05)$. Moreover, APP/PS1 Tg/TRPA1 ${ }^{-/-}$mice showed increased number of times crossing the hidden platform and retention times in the target quadrant (quadrant 4) at day 5 after training (Fig. $2 \mathrm{i}, \mathrm{j}, n=8, P<0.05$ ). The genotypes did not differ in swimming to the visual platform test (Fig. 2k). However, WT, TRPA1 $1^{-/-}$, APP/PS1 Tg and APP/PS1 Tg/TRPA $1^{-/-}$mice showed no difference in the above behaviors and locomotion (Additional file 1: Figure $\mathrm{S} 4, n=8, P>0.05)$. These findings suggest that the TRPA1 channel might be a key regulator in AD-related cognitive performance behavior and spatial learning and memory.

Genetic ablation of function of TRPA1 channels on an APP/PS1 Tg background decreases $A \beta$ deposition in brain lesions and mitigates inflammation but aggravates astrogliosis

To investigate the potential molecular mechanism of TRPA1 channels underlying $\mathrm{AD}$ pathogenesis and $\mathrm{A} \beta$ triggered inflammation, we examined $\mathrm{A} \beta$ plaque deposition in AD lesions of APP/PS1 Tg and APP/PS1 Tg/TRPA1 $-/$ mice. A $\beta$ plaque deposition was markedly decreased in cortex and hippocampus of APP/PS1 Tg/TRPA1 ${ }^{-/-}$ mice (Fig. 3a). Western blot results of $A \beta$ in both oligomers and monomers and $\beta C T F$ within brain lysates from APP/PS1 Tg and APP/PS1 Tg/TRPA $1^{-/-}$mice supported the decreased $A \beta$ plaque deposition in $\mathrm{APP} /$ PS1 Tg/TRPA $1^{-/-}$mice (Fig. 3b, $\left.n=8, P<0.05\right)$. The expression of ABCA1, LRP-1 $(n=8, P<0.05)$ but not apoE $(n=8, P>0.05)$ was decreased in APP/PS1 Tg/ $\mathrm{TRPA}^{-1-}$ mice (Fig. 3c). However, astrogliosis was more severe in APP/PS1 Tg/TRPA1 $1^{-/-}$than APP/PS1 Tg mice (Fig. $4 \mathrm{a}, \mathrm{b}, n=8, P<0.05$ ). Functional loss of TRPA1 channels markedly reduced the levels of the inflammatory cytokines IL- $1 \beta$, IL- 6 and IL- $4(n=8, P<$ $0.05)$ but not anti-inflammatory cytokine IL-10 $(n=8$, $P>0.05$ ) in AD brains (Fig. 4c-f). We next evaluated the activity of NF- $\mathrm{kB}$ and NFAT, major transcription factors regulating the expression of IL-1 $\beta$, IL-6, IL-4 and IL-10 [37-40]. DNA-binding activities of both NF- 


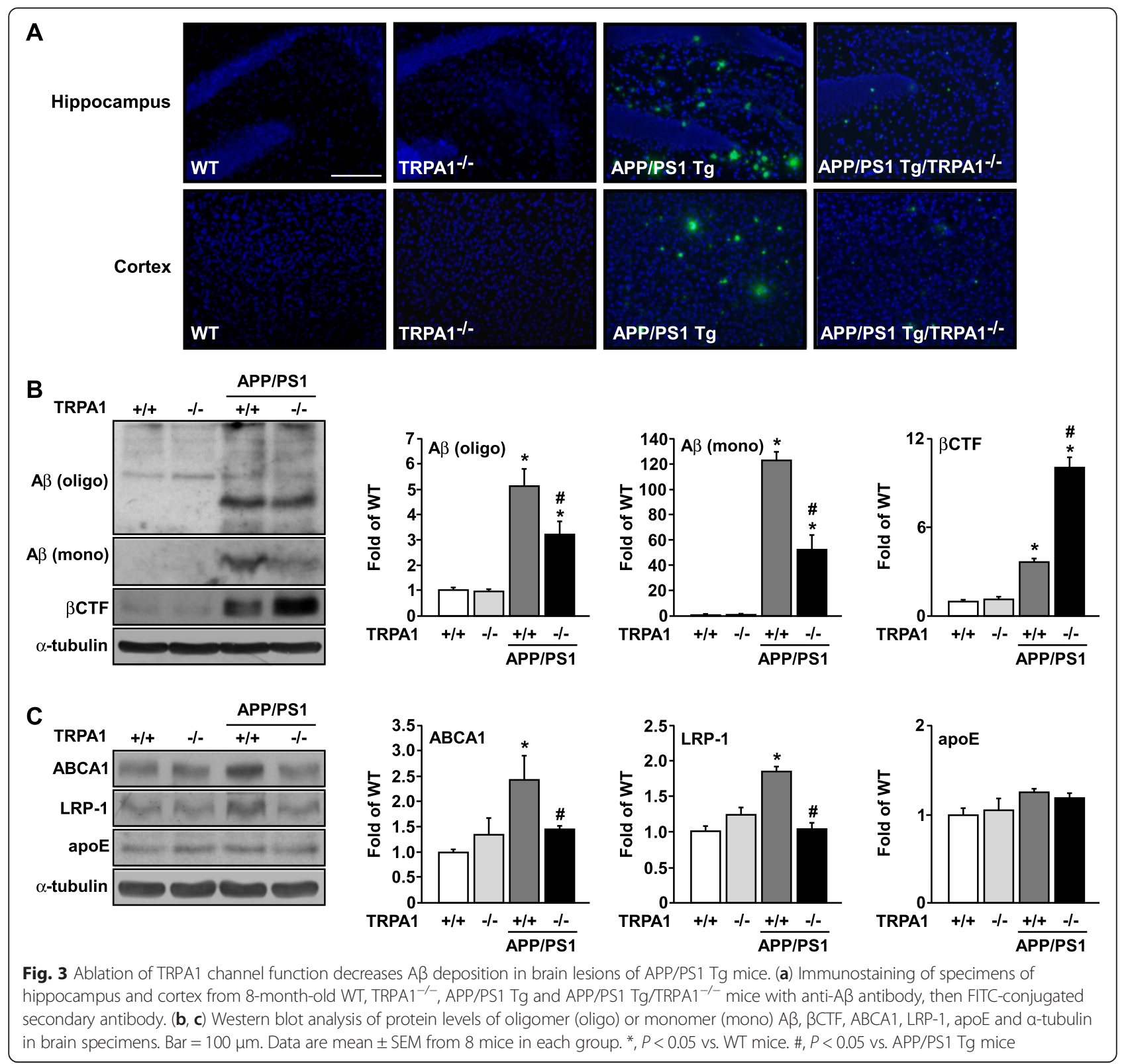

$\kappa \mathrm{B}$ and NFAT were lower with functional deletion of the TRPA1 channel in APP/PS1 Tg/TRPA $1^{-/-}$mice than in APP/PS1 Tg mice (Fig. 4g, $\mathrm{h}, n=8, P<0.05$ ). Immunohistochemistry revealed that IL-1 $\beta$, IL-6, IL-4 and IL-10 were mainly expressed in astrocytes of APP/ PS1 Tg and APP/PS1 Tg/TRPA1 ${ }^{-/-}$mice (Fig. 4i). However, functional ablation of TRPA 1 channels on the C57BL background did not induce $\mathrm{A} \beta$ deposition and inflammation in brains (Fig. $3,4, n=8, P>0.05$ ) but increased astrogliosis (Fig. $4 \mathrm{a}, \mathrm{b}, n=8, P<0.05$ ). The TRPA1 channel may be a key player in regulating $A \beta$ metabolism and inflammatory responses during $\mathrm{AD}$ development.
$A \beta$ - elicited increase in intracellular $\mathrm{Ca}^{2+}$ in astrocytes is TRPA1-dependent

To examine the potential role of TRPA1 channels in the detrimental effect of $\mathrm{A} \beta$ on $\mathrm{AD}$, we first detected the expression of the TRPA1 channel in astrocytes (Fig. 5a). Treatment with fibrilized $A \beta$ did not changes the expression of TRPA1 channels in astrocytes over time (Fig. 5b, $n=5, P>0.05)$. We then investigated whether A $\beta$ could induce functional activation of TRPA1 in astrocytes by treating WT astrocytes with $2 \mu \mathrm{M} A \beta$ for the indicated times. Compared with vehicle treatment, $A \beta$ treatment time-dependently promoted $\mathrm{Ca}^{2+}$ influx within $60 \mathrm{~min}$. The elevated intracellular $\mathrm{Ca}^{2+}$ level occurred as early as 


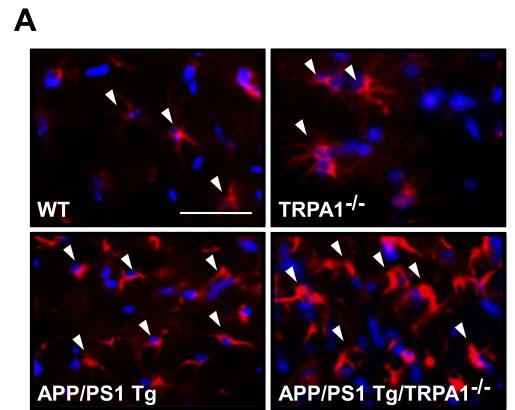

C

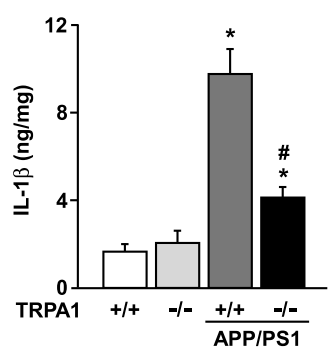

$\mathbf{F}$

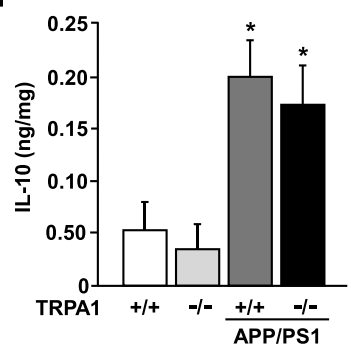

D
B
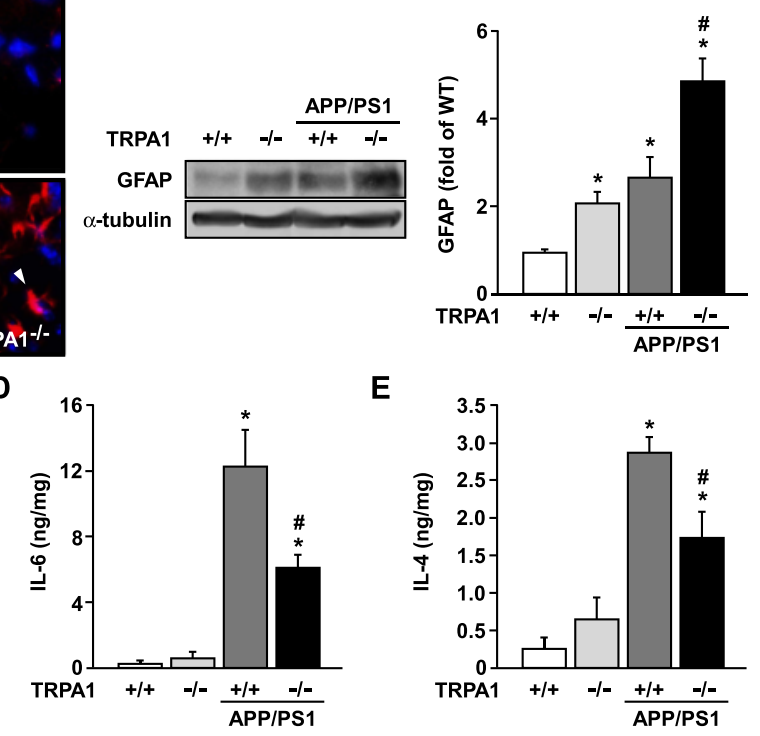

E

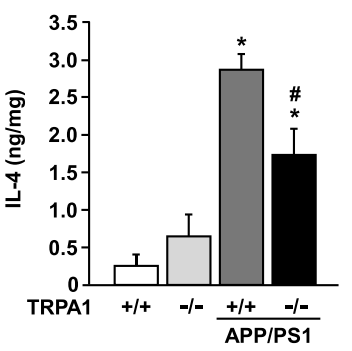

H
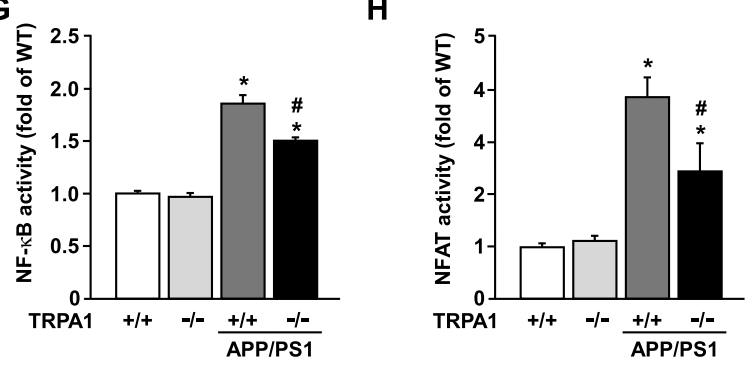

I

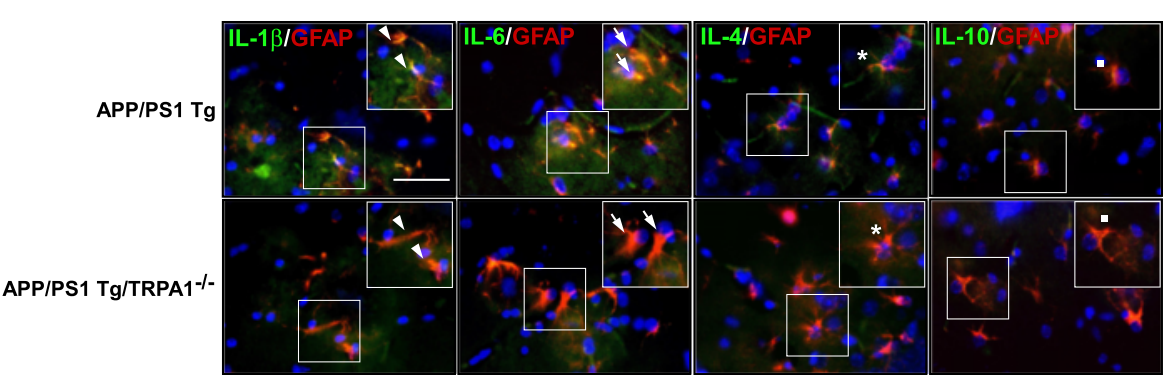

Fig. 4 Genetic disruption of TRPA1 channel function increases astrogliosis but decreases inflammation in hippocampus of APP/PS1 Tg mice. (a) Immunostaining of hippocampus specimens from 8-month-old WT, TRPA $1^{-1-}$, APP/PS1 Tg and APP/PS1 Tg/TRPA ${ }^{-/-}$mice with anti-GFAP antibody, then Texas red-conjugated secondary antibody. (b) Western blot analysis of protein levels of GFAP and a-tubulin. ELISA of (c-f) IL-1 $\beta$, IL-6, IL-4 and IL-10 secretion and $(\mathbf{g}, \mathbf{h})$ NF-KB and NFAT DNA binding activity in brain specimens from 8-month-old WT, TRPA ${ }^{-1-}$, APP/PS1 Tg and APP/PS1 Tg/TRPA1 ${ }^{-1-}$ mice. (i) Immunostaining of hippocampus specimens from 8-month-old APP/PS1 Tg and APP/PS1 Tg/TRPA ${ }^{-/-}$mice with the antibodies anti-GFAP, anti-IL-1 $\beta$, IL-6, IL-4 or IL-10, then FITC- or Texas red-conjugated secondary antibody. Bar $=50 \mu \mathrm{m}$. GFAP-positive cells (red color) denote astrocytes; IL-1 $\beta-$, IL-6-, IL-4- and IL-10-positive astrocytes (green color) are indicated by arrowheads, arrows, stars or dots, respectively. Data are mean \pm SEM from 8 mice in each group. ${ }^{*}, P<0.05$ vs. WT mice. \#, $P<0.05$ vs. APP/PS1 Tg mice

2 min after treatment (Fig. $5 \mathrm{c}, n=5, P<0.05$ ). Additionally, functional deletion of TRPA1, treatment with TRPA1 pharmacological inhibitor HC030031, and pretreatment with EGTA or EDTA all abrogated the fibrilized A $\beta$-increased intracellular $\mathrm{Ca}^{2+}$ level in astrocytes (Fig. 5d$\mathrm{g}, n=5, P<0.05)$. To further investigate the involvement of TRPA1 in $A \beta$-induced $\mathrm{Ca}^{2+}$ influx, we re-expressed full-length human TRPA1 channels in HEK293 cells, which lack TRPA1 channels. TRPA1 channels were successfully expressed in HEK293 cells (Fig. 6a). Treatment with both $A \beta$ and AITC, a TRPA1 selective agonist, significantly increased intracellular $\mathrm{Ca}^{2+}$ level in TRPA1positive HEK293 cells as compared with empty vectortransfected cells, with the increase in intracellular $\mathrm{Ca}^{2+}$ 


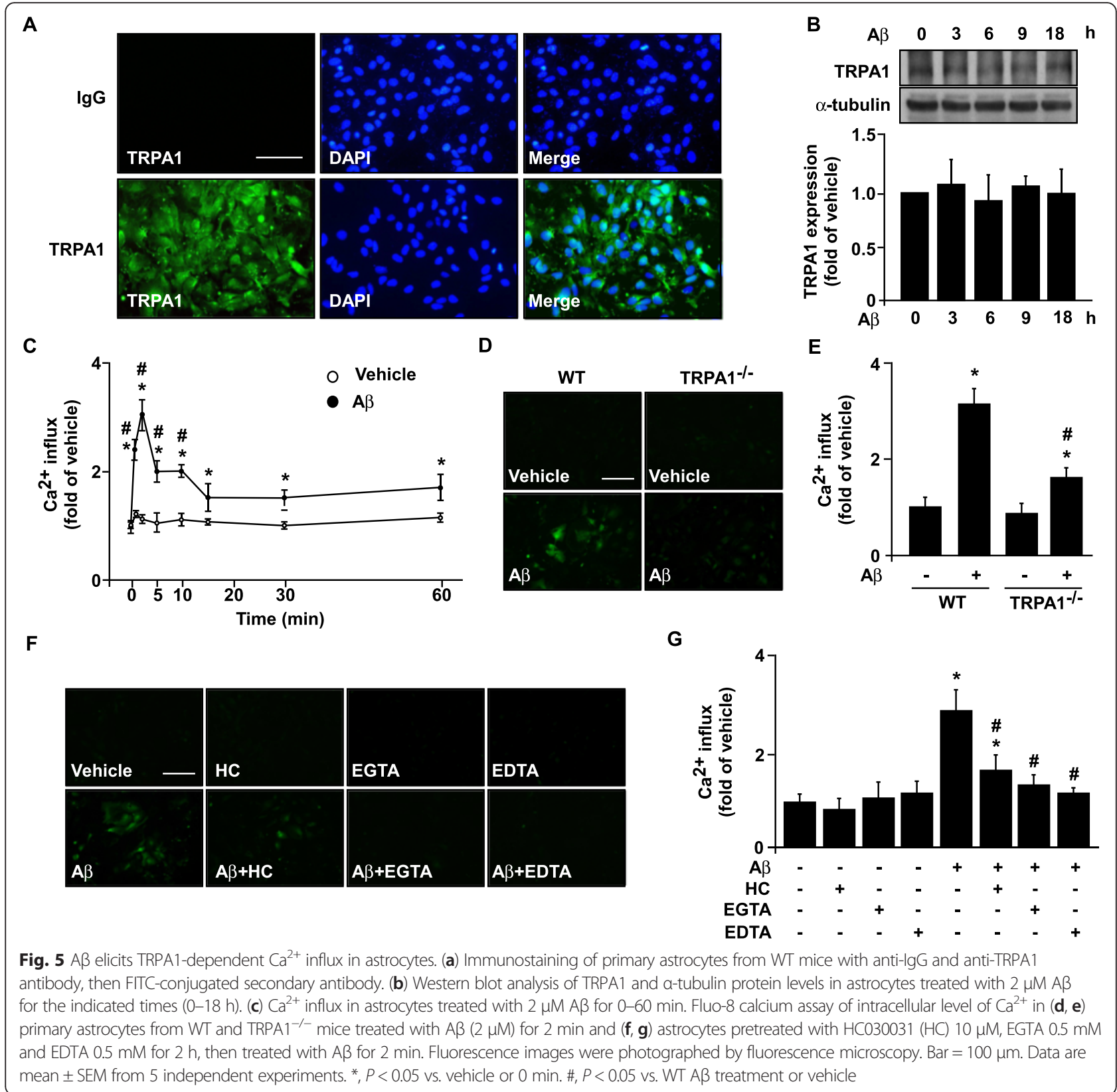

level observed with 1- to 60-min A $\beta$ treatment (Fig. 6b, c, $n=5, P<0.05)$. Blockage of TRPA1 activation by the TRPA1 selective antagonist HC030031 or removal of extracellular $\mathrm{Ca}^{2+}$ by EGTA or EDTA abrogated $\mathrm{A} \beta$ induced $\mathrm{Ca}^{2+}$ influx in TRPA1-reexpressed HEK293 cells (Fig. 6d, $n=5, P<0.05$ ). Therefore, TRPA1 is essential for $\mathrm{A} \beta$-induced $\mathrm{Ca}^{2+}$ mobilization.

TRPA $1-\mathrm{Ca}^{2+}$ signaling plays a crucial role in A $\beta$-mediated PP2B activation, inflammatory responses and astrogliosis in astrocytes

Emerging evidence indicates that $\mathrm{A} \beta$-elevated intracellular $\mathrm{Ca}^{2+}$ level may trigger pro-inflammatory cytokine production by activating $\mathrm{PP} 2 \mathrm{~B}$ and its downstream transcription factors such as NF-kB and NFAT [14-16]. Therefore, we examined whether TRPA1- $\mathrm{Ca}^{2+}$ signaling is involved in $\mathrm{A} \beta$-induced activation of $\mathrm{PP} 2 \mathrm{~B}$, the DNA-binding activities of its downstream targets NF$\kappa \mathrm{B}$ and NFAT, and subsequent inflammatory responses both in vivo and in vitro. We investigated the significance of TRPA1 channels in astrocytes with $A \beta$ treatment in terms of inflammatory responses and astrogliosis. Low fibrilization $A \beta$ triggered the production of IL- 4 and IL-10 in astrocytes, whereas high fibrilization stimulated the production of IL-1 $\beta$ and IL-6 (Additional file 1: Figure S1, $n=5, P<0.05)$. With high fibrillation of $\mathrm{A} \beta$, functional 


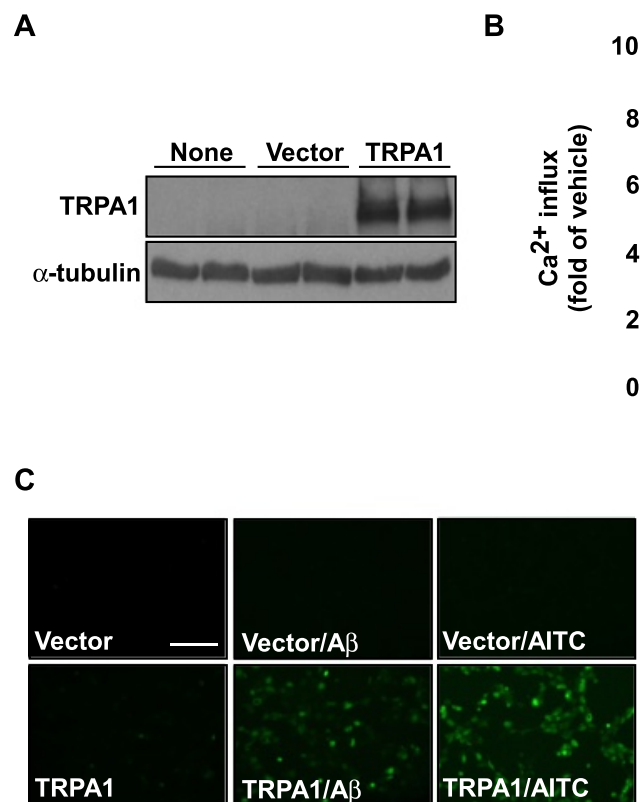

D
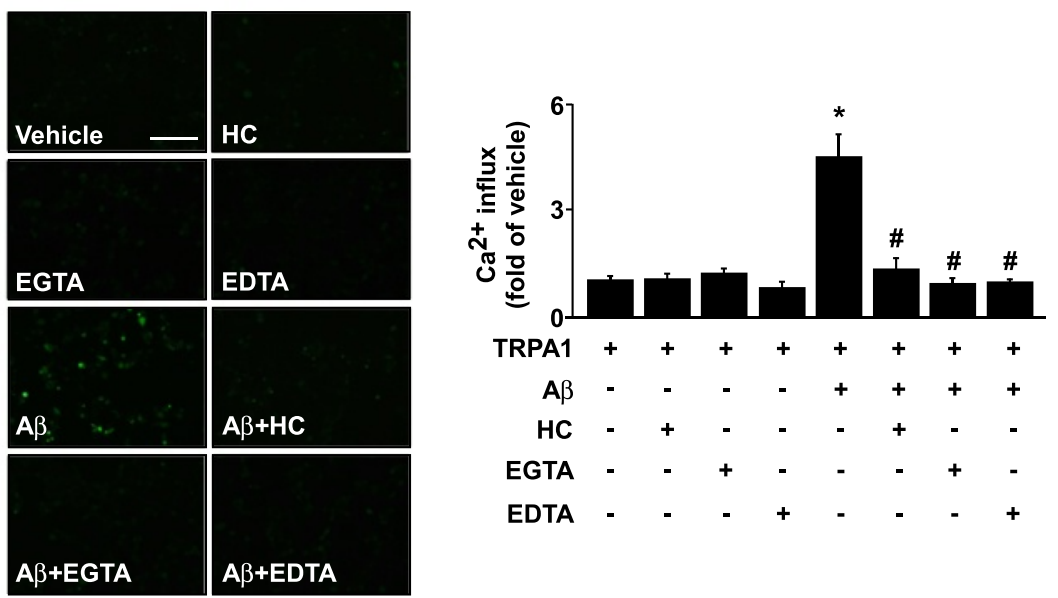

Fig. 6 The essential role of TRPA1 in Aß-induced calcium influx in HEK293 cells. (a) Western blot analysis of TRPA1 and a-tubulin protein levels in non-treated, vector- or TRPA1-transfected HEK293 cells. (b) $\mathrm{Ca}^{2+}$ influx in HEK293 cells transfected with vector or TRPA1 plasmid, then treated with AB (2 $\mu \mathrm{M})$ for 0-60 min. Fluo-8 calcium assay of the intracellular level of $\mathrm{Ca}^{2+}$ in (c) HEK293 cells transfected with vector or TRPA1 plasmid for $24 \mathrm{~h}$, then treated with $\mathrm{A} \beta(2 \mu \mathrm{M})$ or AITC $(10 \mu \mathrm{M}$, a TRPA1 agonist) for 5 min and (d) after transfection with TRPA1 plasmid, HEK293 cells pretreated with a TRPA1 antagonist HC030031 (HC) $10 \mu \mathrm{M}$, EGTA $0.5 \mathrm{mM}$ and EDTA $0.5 \mathrm{mM}$ for $2 \mathrm{~h}$, then with A 3 for 5 min. Fluorescence images were photographed by fluorescence microscopy. Bar $=100 \mu \mathrm{m}$. Data are mean \pm SEM from 5 independent experiments. ${ }^{*}, P<0.05 \mathrm{vs}$. 0 min or TRPA1 transfection alone. \#, $P<0.05$ vs. vector-transfection alone or TRPA1 transfection $+A \beta$ treatment

inhibition of TRPA1 channel activity by HC030031 or genetic manipulation abrogated the $A \beta$-mediated production of IL-1 $\beta$, IL-6, IL-4 and IL-10 in astrocytes (Fig. 7a-d, $n=5, P<0.05)$. Moreover, pretreatment with HC030031 or genetic disruption of TRPA1 function diminished the $\mathrm{A} \beta$-induced activation of NF- $\mathrm{kB}$ and NFAT (Fig. 7e, f, $n=5, P<0.05)$. Exposure of astrocytes to fibrilized $A \beta$ elicited astrogliosis, which was aggravated by pharmacological inhibition or genetic disruption of TRPA1 channel activity (Fig. 7g). As well, PP2B protein was expressed in hippocampus astrocytes of both APP/PS1 Tg and APP/PS1 Tg/TRPA $1^{-1-}$ mice (Fig. 8a). Functional ablation of TRPA1 channels in mice on a C57BL or APP/PS1 Tg background did not affect the protein expression of PP2B (Fig. 8b). However, genetic deletion of TRPA1 in mice on an APP/ PS1 $\mathrm{Tg}$ background decreased PP2B activity in AD brains (Fig. 8c, $\mathrm{n}=8, \mathrm{P}<0.05$ ). Genetic ablation of TRPA1 channel function, treatment with $\mathrm{HC} 030031$, or removal of $\mathrm{Ca}^{2+}$ by EGTA or EDTA all diminished the A $\beta$-increased PP2B activity in astrocytes (Fig. $8 \mathrm{~d}$, e, $n=5, P<0.05$ ). Moreover, 


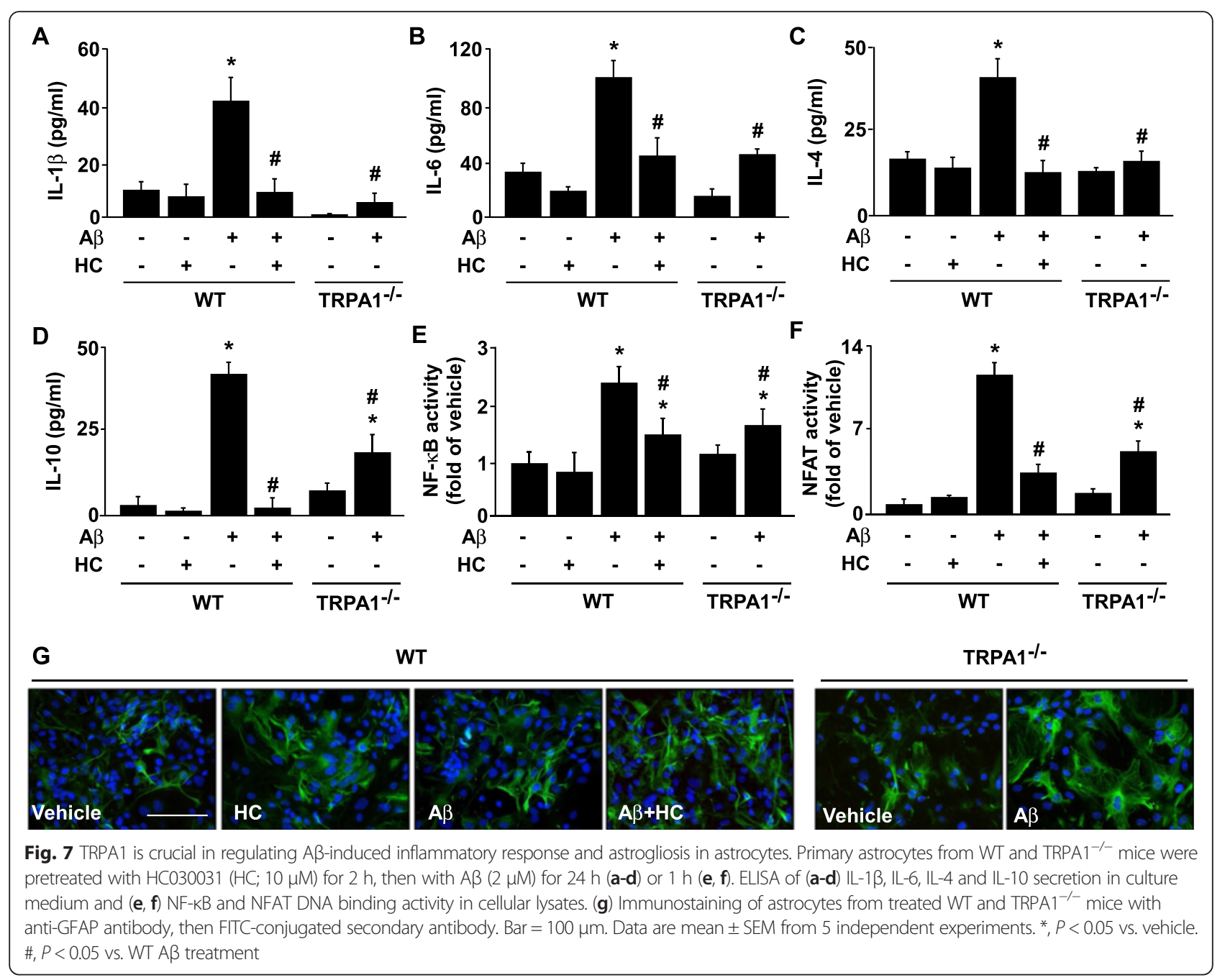

pharmacological inhibition of PP2B activity by CsA or Fen prevented the $A \beta$-induced production of IL- $1 \beta$, IL-6, IL-4 and IL-10 (Fig. 8f-i, $n=5, P<0.05$ ) and activation of NF-kB and NFAT in astrocytes (Fig. 8j, k, $n=5, P<0.05$ ), as well as astrogliosis (Fig. 8l). Collectively, these findings strongly suggest that activation of a TRPA $1-\mathrm{Ca}^{2+}-\mathrm{PP} 2 \mathrm{~B}$ signaling cascade might be an important event in $A \beta$-induced inflammation of astrocytes and AD pathogenesis (Fig. 9).

\section{Discussion}

Our study demonstrated the novel role of the TRPA1 channel in astrocytes under an A $\beta$-elicited inflammatory environment and thus its potential involvement in AD pathogenesis. The protein level of the TRPA1 channel was increased in astrocytes of APP/PS1 Tg mice at 8 months old as compared with WT mice at the same age. As well, loss of function of the TRPA1 channel impeded AD progression, as evidenced by improved nest building ability, spatial learning and memory and decreased $A \beta$ plaque deposition and cytokine production in APP/PS1 Tg mice.
In vitro, TRPA1 channels mediated the $\mathrm{A} \beta$-triggered $\mathrm{Ca}^{2+}$ influx and inflammation in astrocytes. Gain of function of TRPA1 in TRP channel-deficient HEK293 cells further supports that TRPA1 activation is crucial in A $\beta$-mediated $\mathrm{Ca}^{2+}$ influx. A $\beta$ evoked TRPA1- $\mathrm{Ca}^{2+}$ signaling, which in turn activated PP2B, NF- $\mathrm{kB}$ and NFAT. The activation of these proteins increased the production of inflammatory cytokines. This inflammatory cascade in our model agreed with findings by Fernandez et al. and Furman et al., who established that increased $\mathrm{Ca}^{2+}$ influx is a key event for activation of PP2B signaling and inflammation in astrocytes [14-16]. Finally, behavioral analysis demonstrated that functional loss of TRPA1 ameliorated AD progression and improved neuropsychiatric signs, positively affecting cognition and spatial learning and memory. Collectively, our results suggest that the TRPA1 channel is involved in A $\beta$ triggered inflammatory responses of astrocytes and the development of AD.

The association of deregulated cellular $\mathrm{Ca}^{2+}$ homeostasis and $\mathrm{AD}$ pathogenesis has been established in vitro and 


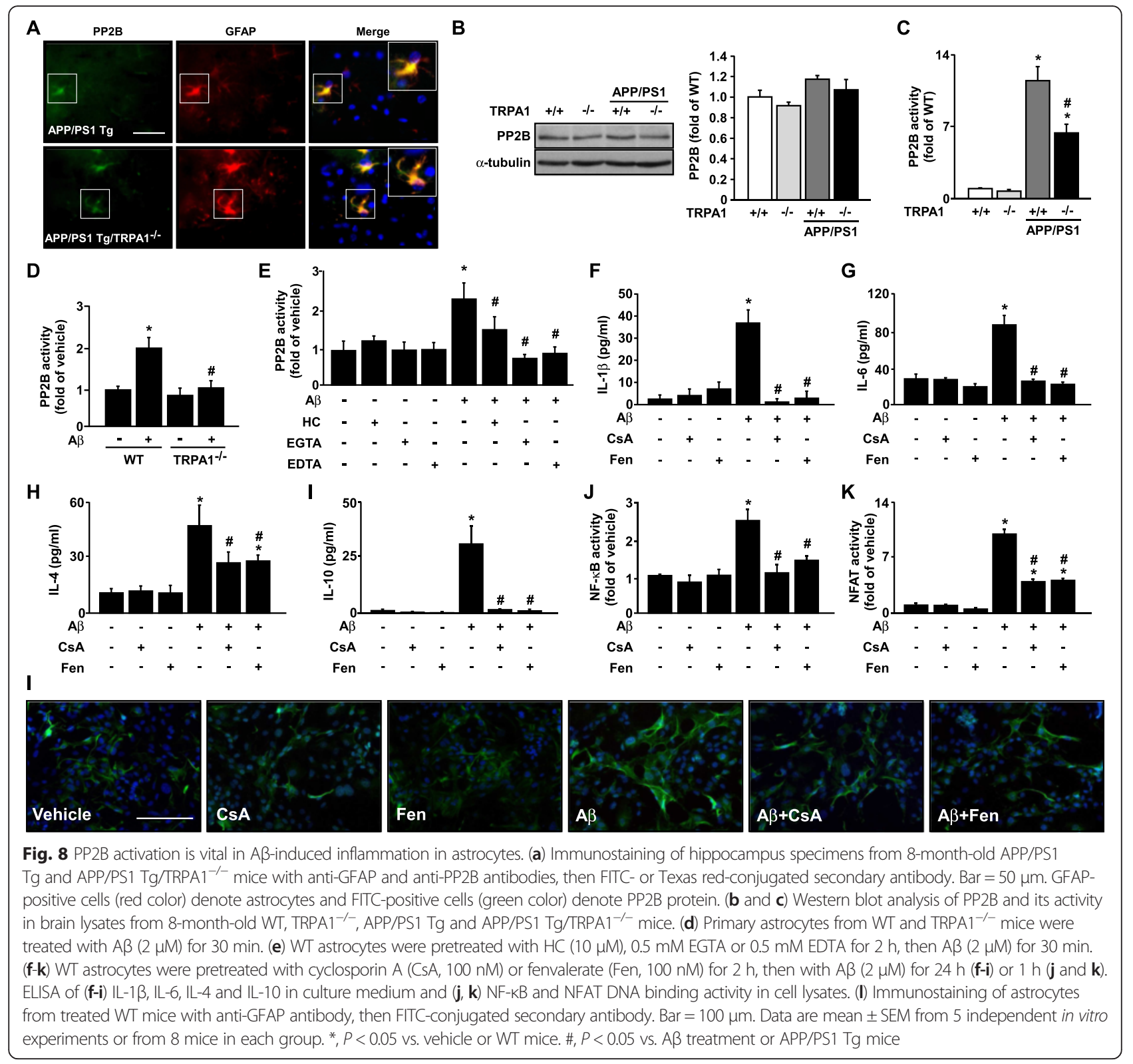

in vivo [41-43]. Emerging evidence further supported the causal relationship between the impaired $\mathrm{Ca}^{2+}$ homeostasis and synaptic dysfunction and neuronal degeneration of $\mathrm{AD}$ [1]. Specifically, exposure of $\mathrm{A} \beta$ to neurons disrupts $\mathrm{Ca}^{2+}$ homeostasis and causes oxidative damage, thereby leading to neuronal death and synaptic dysfunction via multiple receptor-dependent pathways including NMDA receptor or voltage-gated $\mathrm{Ca}^{2+}$ channels [1]. However, research into $\mathrm{Ca}^{2+}$ homeostasis of astrocytes and its role in $\mathrm{AD}$ pathogenesis is still in its infancy. Several lines of evidence indicated that TRP channels such as canonical (TRPC), melastatin (TRPM), and vanilloid (TRPV) channels also play a role in AD pathogenesis [44, 45]. Especially, astrocyte-related inflammation is a key factor in AD progression $[8,9,46,47]$. A $\beta$-induced $\mathrm{Ca}^{2+}$ influx is closely associated with the inflammatory responses in astrocytes [11-13]. In astrocytes, $A \beta$ elicits the production of ROS and nitric oxide (NO), which can activate TRPM2, TRPM7, TRPC5 and TRPV1 and increase the intracellular level of $\mathrm{Ca}^{2+}$, thereby leading to AD-related events in the brain including neurodegeneration and inflammation [30].

However, how TRPA1 activation, particularly in astrocytes, contributes to AD pathogenesis has not been investigated. Our results demonstrated that $\mathrm{A} \beta$ triggered TRPA1dependent $\mathrm{Ca}^{2+}$ influx and subsequently increased PP2B activity, which promoted activation of NF-kB and NFAT, thereby leading to production of pro-inflammatory cytokines from astrocytes. Most importantly, we observed these key events in our in vivo model. Of note, in astrocytes, both pretreatment with $\mathrm{HC} 030031$ and genetic loss of function 


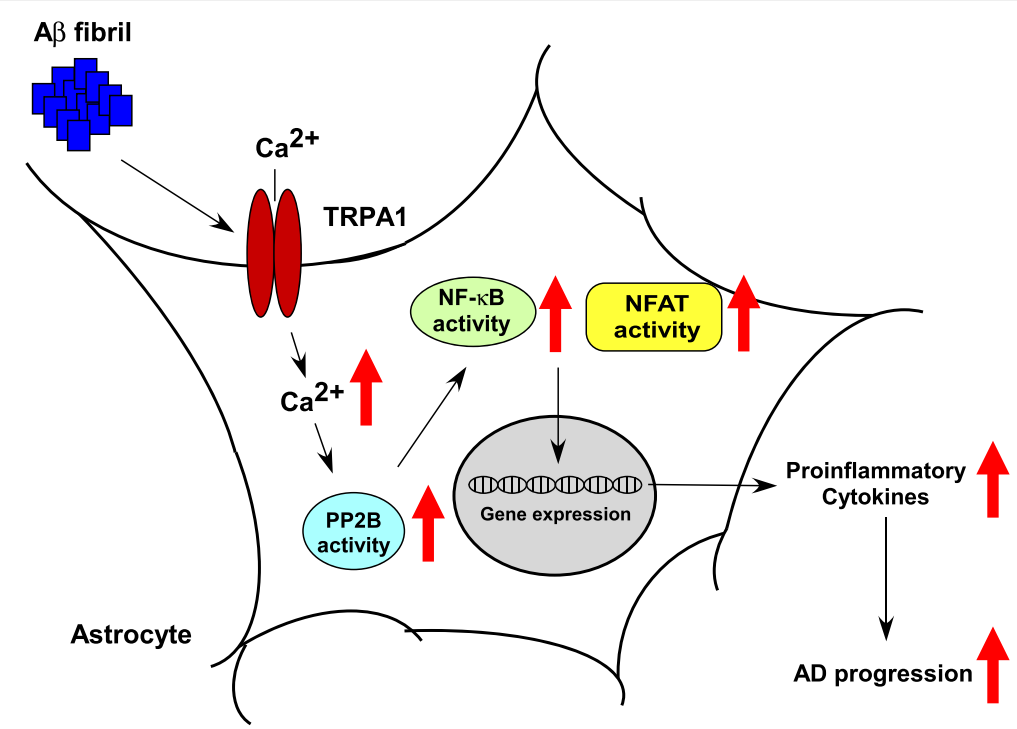

Fig. 9 TRPA1 - $\mathrm{Ca}^{2+}$ - PP2B signaling pathway in AB - triggered activation of NF-KB and NFAT and inflammation in astrocytes. A proposed mechanism by which TRPA1 channel regulates A $\beta$-mediated inflammatory response in astrocytes. A $\beta$ fibril activates PP2B, NF-KB and NFAT and, ultimately, production of pro-inflammatory cytokines in astrocytes

of TRPA1 channels could only partially obstruct the A $\beta$ elicited $\mathrm{Ca}^{2+}$ influx. In contrast, pretreatment with EGTA and EDTA completely abolished $\mathrm{Ca}^{2+}$ influx induced by $A \beta$. These results imply the existence of other routes of $\mathrm{Ca}^{2}$ ${ }^{+}$influx triggered by $\mathrm{A} \beta$. Indeed, several proteins regulating $\mathrm{Ca}^{2+}$ flow on $\mathrm{A} \beta$ challenge in astrocytes have been identified $[42,43]$. In response to ligands, TRP channels can form homo- or heterotetramers or activate other TRP channels, thereby increasing intracellular $\mathrm{Ca}^{2+}$ level and activating downstream $\mathrm{Ca}^{2+}$-mediated signaling cascades [48, 49]. However, whether other TRP channels participate in the A $\beta$-induced TRPA1 channel activation and if so, how they activate the TRPA1 channel remains unknown.

PP2B activity of astrocytes is highly associated with neurodegenerative diseases $[50,51]$. Increased numbers of PP2B-positive astrocytes were found in the immediate vicinity of extracellular $A \beta$ deposition in patients with dementia and in an AD mouse model $[50,51]$. In addition, disruption of $\mathrm{Ca}^{2+}$ homeostasis causes hyperactivity of PP2B signaling cascades, which can amplify the offset effect of $\mathrm{Ca}^{2+}$ dysregulation [15]. This notion was further supported by our findings that TRPA1-derived $\mathrm{Ca}^{2+}$ mobilization was critical in A $\beta$-activated PP2B, as evidenced by reduced PP2B activity in TRPA1 antagonisttreated or TRPA1-deficient astrocytes or brain tissues of APP/PS1 Tg/TRPA1 ${ }^{-/-}$mice. PP2B can lessen Akt activity its downstream signaling pathways, which are involved in inflammation and AD [52-54]. In fact, deletion of TRPA1 decreased PP2B activity but increased the phosphorylation of Akt in brain tissues of APP/PS1 Tg mice (Additional file 1: Figure $\mathrm{S} 5)$. Thus, TRPA $1-\mathrm{Ca}^{2+}-\mathrm{PP} 2 \mathrm{~B}$ signaling may play an important role in $\mathrm{AD}$ progression. However, the detailed molecular mechanism by which $\mathrm{PP} 2 \mathrm{~B}$ regulates $\mathrm{AD}$ progression needs further investigation.

In the $\mathrm{AD}$ brain, $\mathrm{A} \beta$ plaques surrounding astrocytes can secrete inflammatory mediators to regulate neuroinflammation [55]. IL-1 $\beta$, IL-4, and IL-6 are involved in the initiation and progression of $\mathrm{AD}$ by deregulating $\mathrm{A} \beta$-mediated inflammation and APP metabolism [55-57]. In contrast, IL10 can limit inflammation by reducing pro-inflammatory cytokines during $\mathrm{AD}$ pathogenesis [55]. In line with these findings, our data demonstrated lower levels of IL-1 $\beta$, IL-4, IL-6, but IL-10 in APP/PS1 Tg/TRPA1 ${ }^{-/-}$mice than APP/ PS1 Tg mice. Moreover, functional inhibition of TRPA1 abrogated the $A \beta$-triggered production of IL- $1 \beta$, IL- 4 and IL-6 in astrocytes. The transcriptional factors NF- $\mathrm{kB}$ and NFAT are key regulators in gene expression of IL-1 $\beta$, IL-4 and IL-6 [37-40]. Consistently, we found that functional deletion of TRPA1 decreased $A \beta$-induced NF- $\kappa B$ and NFAT activity in astrocytes and mice. Nevertheless, the mechanism underlying TRPA1-mediated regulation of inflammation and $\mathrm{AD}$ pathogenesis needs further investigation.

Astrogliosis (referred to as reactive astrocytes) occurs prominently in response to central nervous system injury or remodeling $[9,58]$. Although the biological function of astrogliosis is not fully understood, reactive astrocytes are intimately associated with $\mathrm{A} \beta$ plaque and involved in the regulation of neural protection and repair, glial scarring and neuro-inflammation in the pathogenesis of AD [58]. In addition, reactive astrocytes promote the clearance and degradation of $\mathrm{A} \beta$ in $\mathrm{AD}$ brain and thus limit the growth of $A \beta$ plaque [59]. Interestingly, we found greater astrogliosis after treatment with a TRPA1 antagonist or 
functional deletion of TRPA1 in vitro and in vivo. In parallel, the neuro-inflammation was ameliorated with both pharmacological inhibition and genetic deletion of TRPA1 in $A \beta$-treated astrocytes and mouse brains. Activation of TRPA1- $\mathrm{Ca}^{2+}$ signaling might be critical in regulating A $\beta$ mediated astrogliosis and neuro-inflammation.

APP can be rapidly metabolized by post-translational proteolysis via an amyloidogenic or non-amyloidogenic pathway in neurons, and its role in $\mathrm{AD}$ is well established $[3,60]$. In the amyloidogenic pathway, APP is cleaved by $\beta$ secretase, and N-terminal APP fragments and $\beta C T F$ are produced and released. $\beta$ CTF is then cleaved by $\gamma$-secretase and generates an amyloid precursor protein intracellular domain and toxic $\mathrm{A} \beta$ peptide (37-49 amino acids), which triggers inflammation and neuron dysfunction $[3,5,60]$. In contrast, in the non-amyloidogenic pathway, APP is cleaved by $\alpha$-secretase and yields a soluble N-terminal APP $\alpha$ fragment and $\alpha$-C-terminal fragment $(\alpha C T F) . \alpha C T F$ is then cleaved by $\gamma$-secretase to generate non-toxic p83 peptide (23-25 amino acids) [60, 61]. Disruption of $\mathrm{Ca}^{2+}$ homeostasis may deregulate APP processing and increase $A \beta$ generation [61]. This notion was supported by our findings that ablation of TRPA1- $\mathrm{Ca}^{2+}$ signaling decreased $\mathrm{A} \beta$ production and accumulation in the $\mathrm{AD}$ mouse brain. Notably, our results further demonstrated that functional loss of TRPA1 channels increased the levels of $\beta C T F$ but decreased that of $\mathrm{A} \beta$ in the $\mathrm{AD}$ mouse brain. Thus, TRPA1- $\mathrm{Ca}^{2+}$ signaling might regulate APP processing, especially at the step of cleavage of $\beta C T F$ to $A \beta$ generation.

Previous evidence linked cholesterol metabolism of the brain to $A \beta$ clearance $[62,63]$. Astrocyte-derived apoEcontaining high-density lipoprotein-like particles play a central role in neural repair during $\mathrm{AD}$ development [62-64]. These particles can be transported by ABCA1 into the extracellular space to bind with $A \beta$ and then are taken up by neurons, astrocytes and microglia through LRP-1 to remove the $A \beta$ deposition [63]. The expression of $A B C A 1$ and LRP-1 is increased with AD progression $[65,66]$. We found that functional loss of TRPA1 channels decreased the expression of ABCA1 and LRP-1 without altering apoE expression and its co-localization with $A \beta$ plaque in APP/PS1 Tg mice. As we described previously, $A \beta$ accumulation was lower in the brain of APP/PS1 Tg/TRPA1 ${ }^{-/-}$than APP/PS1 Tg mice, so APP/ PS1 Tg/TRPA ${ }^{-/-}$mice might not need such levels of ABCA1 and LRP-1 to clear A $\beta$. Nevertheless, we cannot conclude that TRPA1 channels are a negative regulator of $A \beta$ clearance based on these observations.

\section{Conclusions}

In conclusion, we provide experimental evidence to support the critical role of TRPA1- $\mathrm{Ca}^{2+}$ signaling in regulating $\mathrm{A} \beta$-triggered inflammation and $\mathrm{AD}$ progression. The molecular mechanisms we established may provide important information for depicting the pathogenesis of $\mathrm{AD}$ and aid in the development of therapeutic interventions for $\mathrm{AD}$ and other neurodegenerative diseases.

\section{Additional file}

Additional file 1: Supplementary figures. (PDF 547 kb)

\section{Abbreviations}

ABCA1: ATP-binding cassette transporter A1; AD: Alzheimer's disease; AITC: allyl isothiocyanate; apoE: apolipoprotein E; APP: amyloid precursor protein; $A \beta$ : amyloid- $\beta$; aCTF: $\alpha$-C-terminal fragment; BACE1: $\beta$-site APP cleavage enzyme

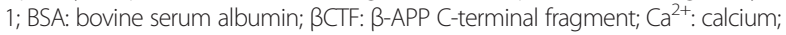
EDTA: ethylenediaminetetraacetic acid; EGTA: ethylene glycol tetraacetic acid; GFAP: glial fibrillary acidic protein; HEK293: human embryonic kidney 293; IBA1: ionized calcium-binding adapter molecule 1; IL: interleukin; LRP-1: LDLR-related protein 1; MWM: Morris water maze; NFAT: nuclear factor of activated T cells; NO: nitric oxide; PP2B: protein phosphatase 2B; PS1: presenilin 1; ROS: reactive oxygen species; TRPA1: transient receptor potential ankyrin 1; TRPC: transient receptor potential canonical; TRPM: transient receptor potential melastatin; TRPV: transient receptor potential vanilloid; VWF: von Willebrand factor.

\section{Competing interests}

The authors declare that they have no competing interests.

\section{Authors' contributions}

$\mathrm{KIL}, \mathrm{HTL}, \mathrm{HCL}$ and FCT performed experiments and analyzed the data. HJT, SKS and TSL designed the experiments and TSL wrote the paper. All authors have read and approved the submission of the manuscript.

\section{Acknowledgments}

The authors thank Laura Smales for help in language editing. This study was supported by grants from Ministry of Science and Technology (MOST-102-2628B-010-001-MY3, MOST-103-2628-B-010-040-MY3 and MOST-104-2320-B-010-041MY3), Yen Tjing Ling Medical Foundation (Cl-104-10 and Cl-104-13) and Ministry of Education, Aim for the Top University Plan, Taiwan.

\section{Author details}

${ }^{1}$ Department of Physiology, School of Medicine, National Yang-Ming University, Taipei, Taiwan. ${ }^{2}$ Institute of Anatomy and Cell Biology, National Yang-Ming University, Taipei, Taiwan. ${ }^{3}$ Institute of Neuroscience, School of Life Science, National Yang-Ming University, Taipei, Taiwan. ${ }^{4}$ International Graduate Program, Interdisciplinary Neuroscience Program, Taipei, Taiwan. ${ }^{5}$ Cardiovascular Division, Institute of Biomedical Sciences, Academia Sinica, Taipei, Taiwan. ${ }^{6}$ Genome Research Center, National Yang-Ming University, Taipei, Taiwan.

Received: 18 January 2016 Accepted: 19 April 2016 Published online: 27 April 2016

\footnotetext{
References

1. Querfurth HW, LaFerla FM. Alzheimer's disease. N Engl J Med. 2010;362:329-44.

2. Kawas CH. Clinical practice. Early Alzheimer's disease. N Engl J Med. 2003; 349:1056-63.

3. Haass C, Selkoe DJ. Soluble protein oligomers in neurodegeneration: lessons from the Alzheimer's amyloid $\beta$-peptide. Nat Rev Mol Cell Biol. 2007;8:101-12.

4. Jack Jr CR. Alzheimer disease: new concepts on its neurobiology and the clinical role imaging will play. Radiology. 2012;263:344-61.

5. Tanzi RE, Bertram L. Twenty years of the Alzheimer's disease amyloid hypothesis: a genetic perspective. Cell. 2005;120:545-55.

6. Heneka MT, Golenbock DT, Latz E. Innate immunity in Alzheimer's disease. Nat Immunol. 2015;16:229-36.

7. Morales I, Guzmán-Martínez L, Cerda-Troncoso C, Farías GA, Maccioni RB. Neuroinflammation in the pathogenesis of Alzheimer's disease. A rational framework for the search of novel therapeutic approaches. Front Cell Neurosci. 2014:8:112

8. Rodríguez JJ, Olabarria M, Chvatal A, Verkhratsky A. Astroglia in dementia and Alzheimer's disease. Cell Death Differ. 2009;16:378-85.
} 
9. Verkhratsky A, Olabarria M, Noristani HN, Yeh CY, Rodriguez JJ. Astrocytes in Alzheimer's disease. Neurotherapeutics. 2010;7:399-412.

10. Zhang F, Jiang L. Neuroinflammation in Alzheimer's disease. Neuropsychiatr Dis Treat. 2015;11:243-56.

11. Abramov AY, Canevari L, Duchen MR. Calcium signals induced by amyloid beta peptide and their consequences in neurons and astrocytes in culture. Biochim Biophys Acta. 2004;1742:81-7.

12. Maragakis NJ, Rothstein JD. Mechanisms of Disease: astrocytes in neurodegenerative disease. Nat Clin Pract Neurol. 2006;2:679-89.

13. Ronco V, Grolla AA, Glasnov TN, Canonico PL, Verkhratsky A, Genazzani AA, et al. Differential deregulation of astrocytic calcium signaling by amyloid- $\beta$, TNFa, IL-1 $\beta$ and LPS. Cell Calcium. 2014;55:219-29.

14. Fernandez AM, Fernandez S, Carrero P, Garcia-Garcia M, Torres-Aleman I. Calcineurin in reactive astrocytes plays a key role in the interplay between proinflammatory and anti-inflammatory signals. J Neurosci. 2007;27:8745-56

15. Furman $\mathrm{JL}$, Norris $\mathrm{CM}$. Calcineurin and glial signaling: neuroinflammation and beyond. J Neuroinflammation. 2014;11:158.

16. Lim D, lyer A, Ronco V, Grolla AA, Canonico PL, Aronica E, et al. Amyloid beta deregulates astroglial mGluR5-mediated calcium signaling via calcineurin and NF-KB. Glia. 2013;61:1134-45.

17. Benemei S, Patacchini R, Trevisani M, Geppetti P. TRP channels. Curr Opin Pharmacol. 2015;22:18-23.

18. Caterina MJ. Chemical biology: sticky spices. Nature. 2007:445:491-2

19. De Petrocellis L, Ligresti A, Moriello AS, Allarà M, Bisogno T, Petrosino S, et al. Effects of cannabinoids and cannabinoid-enriched Cannabis extracts on TRP channels and endocannabinoid metabolic enzymes. Br J Pharmacol. 2011;163:1479-94.

20. Zygmunt PM, Högestätt ED. TRPA1. Handb Exp Pharmacol. 2014;222:583-630

21. Anand U, Otto WR, Facer P, Zebda N, Selmer I, Gunthorpe MJ, et al. TRPA] receptor localisation in the human peripheral nervous system and functional studies in cultured human and rat sensory neurons. Neurosci Lett. 2008:438:221-7.

22. Jo KD, Lee KS, Lee WT, Hur MS, Kim HJ. Expression of transient receptor potential channels in the ependymal cells of the developing rat brain. Anat Cell Biol. 2013;46:68-78.

23. Salas MM, Hargreaves KM, Akopian AN. TRPA1-mediated responses in trigeminal sensory neurons: interaction between TRPA1 and TRPV1. Eur J Neurosci. 2009:29:1568-78.

24. Shigetomi E, Tong X, Kwan KY, Corey DP, Khakh BS. TRPA1 channels regulate astrocyte resting calcium and inhibitory synapse efficacy through GAT-3. Nat Neurosci. 2011;15:70-80.

25. Shigetomi E, Jackson-Weaver O, Huckstepp RT, O'Dell TJ, Khakh BS. TRPA1 channels are regulators of astrocyte basal calcium levels and long-term potentiation via constitutive D-serine release. J Neurosci. 2013;33:10143-53.

26. Bautista DM, Jordt SE, Nikai T, Tsuruda PR, Read AJ, Poblete J, et al. TRPA1 mediates the inflammatory actions of environmental irritants and proalgesic agents. Cell. 2006;124:1269-82.

27. Bautista DM, Pellegrino M, Tsunozaki M. TRPA1: A gatekeeper for inflammation. Annu Rev Physiol. 2013;75:181-200.

28. Meseguer V, Alpizar YA, Luis E, Tajada S, Denlinger B, Fajardo O, et al. TRPA1 channels mediate acute neurogenic inflammation and pain produced by bacterial endotoxins. Nat Commun. 2014;5:3125.

29. Takada Y, Numata T, Mori Y. Targeting TRPs in neurodegenerative disorders. Curr Top Med Chem. 2013;13:322-34.

30. Yamamoto S, Wajima T, Hara Y, Nishida M, Mori Y. Transient receptor potential channels in Alzheimer's disease. Biochim Biophys Acta. 2007;1772:958-67.

31. Coraci IS, Husemann J, Berman JW, Hulette C, Dufour JH, Campanella GK, et al. CD36, a class B scavenger receptor, is expressed on microglia in Alzheimer's disease brains and can mediate production of reactive oxygen species in response to beta-amyloid fibrils. Am J Pathol. 2002;160:101-12.

32. Bamberger ME, Harris ME, McDonald DR, Husemann J, Landreth GE. A cell surface receptor complex for fibrillar beta-amyloid mediates microglial activation. J Neurosci. 2003;23:2665-74.

33. Benito C, Tolón RM, Castillo Al, Ruiz-Valdepeñas L, Martínez-Orgado JA, Fernández-Sánchez FJ, et al. $\beta$-Amyloid exacerbates inflammation in astrocytes lacking fatty acid amide hydrolase through a mechanism involving PPAR-a, PPAR- $y$ and TRPV1, but not $\mathrm{CB}_{1}$ or $\mathrm{CB}_{2}$ receptors. $\mathrm{Br} J$ Pharmacol. 2012:166:1474-89.

34. Zhou S, Wu H, Zeng C, Xiong X, Tang S, Tang Z, et al. Apolipoprotein E protects astrocytes from hypoxia and glutamate-induced apoptosis. FEBS Lett. 2013;587:254-8.
35. Filali M, Lalonde R. Age-related cognitive decline and nesting behavior in an APPswe/PS1 bigenic model of Alzheimer's disease. Brain Res. 2009;1292:93-9.

36. Jung WR, Kim HG, Kim KL. Ganglioside GQ1b improves spatial learning and memory of rats as measured by the Y-maze and the Morris water maze tests. Neurosci Lett. 2008;439:220-5.

37. Libermann TA, Baltimore D. Activation of interleukin- 6 gene expression through the NF-kappa B transcription factor. Mol Cell Biol. 1990;10:2327-34.

38. Cogswell JP, Godlevski MM, Wisely GB, Clay WC, Leesnitzer LM, Ways JP, et al. NF-kappa B regulates IL-1 beta transcription through a consensus NF-KB binding site and a nonconsensus CRE-like site. J Immunol. 1994;153:712-23.

39. Rincón M, Flavell RA. Transcription mediated by NFAT is highly inducible in effector CD4+ T helper 2 (Th2) cells but not in Th1 cells. Mol Cell Biol. 1997; 17:1522-34.

40. Fric J, Zelante T, Wong AY, Mertes A, Yu HB, Ricciardi-Castagnoli P. NFAT control of innate immunity. Blood. 2012:120:1380-9.

41. Hölscher C. Possible causes of Alzheimer's disease: amyloid fragments, free radicals, and calcium homeostasis. Neurobiol Dis. 1998:5:129-41.

42. Haughey NJ, Mattson MP. Alzheimer's amyloid beta-peptide enhances ATP/ gap junction-mediated calcium-wave propagation in astrocytes. Neuromolecular Med. 2003;3:173-80.

43. Verkhratsky A. Glial calcium signaling in physiology and pathophysiology. Acta Pharmacol Sin. 2006;27:773-80.

44. Vriens J, Owsianik G, Voets T, Droogmans G, Nilius B. Invertebrate TRP proteins as functional models for mammalian channels. Pflugers Arch. 2004; 449:213-26.

45. Montell C. The TRP superfamily of cation channels. Sci STKE. 2005;2005:re3.

46. Bouvier DS, Murai KK. Synergistic actions of microglia and astrocytes in the progression of Alzheimer's disease. J Alzheimers Dis. 2015;45:1001-14.

47. Fakhoury M. Role of immunity and inflammation in the pathophysiology of neurodegenerative diseases. Neurodegener Dis. 2015;15:63-9.

48. Pan Z, Yang H, Reinach PS. Transient receptor potential (TRP) gene superfamily encoding cation channels. Hum Genomics. 2001;5:108-16.

49. Su KH, Lin SJ, Wei J, Lee KI, Zhao JF, Shyue SK, et al. The essential role of transient receptor potential vanilloid 1 in simvastatin-induced activation of endothelial nitric oxide synthase and angiogenesis. Acta Physiol (Oxf). 2014; 212:191-204.

50. Norris CM, Kadish I, Blalock EM, Chen KC, Thibault V, Porter NM, et al. Calcineurin triggers reactive/inflammatory processes in astrocytes and is upregulated in aging and Alzheimer's models. J Neurosci. 2005;25: 4649-58.

51. Abdul HM, Sama MA, Furman $\mathrm{JL}$, Mathis DM, Beckett TL, Weidner AM, et al. Cognitive decline in Alzheimer's disease is associated with selective changes in calcineurin/NFAT signaling. J Neurosci. 2009;29: 12957-69.

52. Rickle A, Bogdanovic N, Volkman I, Winblad B, Ravid R, Cowburn RF. Akt activity in Alzheimer's disease and other neurodegenerative disorders. Neuroreport. 2004;15:955-9.

53. Park CH, Kim YS, Kim YH, Choi MY, Yoo JM, Kang SS, et al. Calcineurin mediates AKT dephosphorylation in the ischemic rat retina. Brain Res. 2008;1234:148-57.

54. Kitagishi $Y$, Nakanishi A, Ogura Y, Matsuda S. Dietary regulation of PI3K/AKT/ GSK-3ß pathway in Alzheimer's disease. Alzheimers Res Ther. 2014;6:35.

55. Rubio-Perez JM, Morillas-Ruiz JM. A review: inflammatory process in Alzheimer's disease, role of cytokines. Sci World J. 2012;2012:756357.

56. Mrak RE, Griffin WS. Interleukin-1, neuroinflammation, and Alzheimer's disease. Neurobiol Aging. 2001;22:903-8.

57. Chakrabarty P, Tianbai L, Herring A, Ceballos-Diaz C, Das P, Golde TE. Hippocampal expression of murine IL-4 results in exacerbation of amyloid deposition. Mol Neurodegener. 2012;7:36

58. Pekny M, Pekna M. Astrocyte reactivity and reactive astrogliosis: costs and benefits. Physiol Rev. 2014;94:1077-98.

59. Kraft AW, Hu X, Yoon $\mathrm{H}$, Yan $\mathrm{P}$, Xiao Q, Wang $\mathrm{Y}$, et al. Attenuating astrocyte activation accelerates plaque pathogenesis in APP/PS1 mice. FASEB J. 2013;27:187-98.

60. Lazarov O, Demars MP. All in the Family: How the APPs Regulate Neurogenesis. Front Neurosci. 2012;6:81

61. LaFerla FM. Calcium dyshomeostasis and intracellular signalling in Alzheimer's disease. Nat Rev Neurosci. 2002;3:862-72.

62. Di Paolo G, Kim TW. Linking lipids to Alzheimer's disease: cholesterol and beyond. Nat Rev Neurosci. 2011;12:284-96.

63. Liu CC, Kanekiyo T, Xu H, Bu G. Apolipoprotein E and Alzheimer disease: risk, mechanisms and therapy. Nat Rev Neurol. 2013;9:106-18. 
64. Dietschy JM, Turley SD. Cholesterol metabolism in the brain. Curr Opin Lipidol. 2001;12:105-12.

65. Barbero-Camps E, Fernández A, Baulies A, Martinez L, Fernández-Checa JC, Colell A. Endoplasmic reticulum stress mediates amyloid $\beta$ neurotoxicity via mitochondrial cholesterol trafficking. Am J Pathol. 2014;184:2066-81.

66. Kanekiyo T, Bu G. The low-density lipoprotein receptor-related protein 1 and amyloid- $\beta$ clearance in Alzheimer's disease. Front Aging Neurosci. 2014;6:93.

Submit your next manuscript to BioMed Central and we will help you at every step:

- We accept pre-submission inquiries

- Our selector tool helps you to find the most relevant journal

- We provide round the clock customer support

- Convenient online submission

- Thorough peer review

- Inclusion in PubMed and all major indexing services

- Maximum visibility for your research

Submit your manuscript at www.biomedcentral.com/submit
Biomed Central 